Article

\title{
Enhanced Production and Quantitative Evaluation of Nigericin from the Algerian Soil-Living Streptomyces youssoufiensis SF10 Strain
}

\author{
Nassima Leulmi 1,2,3, Denise Sighel 1,4, Andrea Defant ${ }^{1}$, Karima Khenaka ${ }^{2}$, \\ Abderrahmane Boulahrouf ${ }^{2}$ (D) and Ines Mancini ${ }^{1, *(D)}$ \\ 1 Laboratory of Bioorganic Chemistry, Department of Physics, University of Trento, via Sommarive 14, \\ I-38123 Povo-Trento, Italy; leulminassima@gmail.com (N.L.); denise.sighel@unitn.it (D.S.) \\ andrea.defant@unitn.it (A.D.) \\ 2 Microbiological Laboratory Engineering and Application, Mentouri Brothers University, \\ Constantine 25000, Algeria; karima_kh86@yahoo.fr (K.K.); boulahroufabderrahmane@yahoo.fr (A.B.) \\ 3 Department of Cellular and Molecular Biology, University Abbes Laghrour Khenchela, \\ Khenchela 40000, Algeria \\ 4 Laboratory of Translational Genomics, Department CIBIO, University of Trento, Via Sommarive 9, \\ I-38123 Povo-Trento, Italy \\ * Correspondence: ines.mancini@unitn.it; Tel.: +39-0461-281548
}

Received: 18 December 2018; Accepted: 22 January 2019; Published: 26 January 2019

\begin{abstract}
Nigericin, one of the main ionophoric polyethers produced by various Streptomyces strains, presents relevant biological activities including antibacterial and recently studied antitumor properties. This work describes the influence of different culture conditions on the production of this metabolite by Streptomyces sp. SF10, isolated from a semi-arid soil sample collected at Chélia Mountain, in Khenchela (Northeastern Algeria) and identified as Streptomyces youssoufiensis. The extracts from the strain, cultured in a solid state or submerged fermentation conditions, using several carbon sources at different $\mathrm{pH}$ values, in the presence or absence of iron (II) sulfate and in co-culture with other Streptomyces species, were analyzed using a high-performance liquid chromatography (HPLC) system equipped with an evaporative light scattering detector (ELSD). The best culture conditions provided a concentration of nigericin of $0.490 \pm 0.001 \mathrm{mg} / \mathrm{mL}$ in the extract. The HPLC-ELSD method, optimized here for the quantitative detection of nigericin, can find wider applications in the analysis of several other metabolites characterized by a similar polycyclic polyether structure or, more generally, by the lack of significant chromophores in their molecular structure.
\end{abstract}

Keywords: polyether ionophores; nigericin; HPLC analysis; Actinobacteria; Streptomyces; fermentation; culture media

\section{Introduction}

Bacteria are a rich source of metabolites with relevant biological and therapeutic properties, of current interest for their biotechnological exploitation. Often, the bacterial metabolite profile is affected by the conditions of the particular ecosystem where a given bacterial strain lives, such as temperature, radiation and salt concentration, as in the case of the extremophilic Actinobacteria [1]. Streptomyces sp. (family Streptomycetaceae, order Actinomycetales), the largest genus of Actinobacteria, produces a wide series of polyether antibiotics, structurally characterized by the presence of a series of fused heterocyclic oxygen-containing rings and stereogenic centers [2]. Due to their ability to bind monovalent or multivalent cations, these polycyclic polyethers form lipid soluble complexes, 
able to transport metal cations across the cell membrane, causing the loss of membrane integrity and subsequent cell death [3].

In light of their highly complex structures and stereochemistry, the method of choice for the production of these compounds remains the fermentation process based on the use of a suitable bacteria strain. This method gives practical advantages in obtaining enantiopure forms, compared to organic synthesis.

The efficiency of metabolite production by fermentation in terms of yield, ease in the extraction workup, and separation, is significantly affected by the choice of the medium and the conditions used. The relationship between the composition of the culture media and metabolite biosynthesis has been deeply investigated [4,5], for example, it was observed that the metabolite production by Streptomyces is related to both nutritional parameters and conditions used for its culture [6,7]. It is known that the concentrations of some components in the medium play a crucial role in the onset and intensity of secondary metabolism [8]. Nutritional requirements vary from strain to strain, therefore, the most suitable fermentation conditions, the appropriate medium components and other parameters have to be identified and optimized accordingly [9]. Studies comparing submerged-state and solid-state fermentations (SSF) proved the particular advantage of using solid-state fermentation in terms of higher quantities [10] and chemo-diversity of the bioactive metabolites obtained [11]. The sporulation, which is usually absent in liquid fermentation, is also able to affect the metabolite production [12]. The $\mathrm{pH}$ value of the culture medium also affects the cell membrane function, the cell morphology and the molecular structure of metabolites [13]. In the case of Streptomyces, different metabolites can be produced by the same microorganism in different $\mathrm{pH}$ environmental conditions. Finally, recent studies have focused on the co-fermentation of different microorganisms in a single environment as a tool to obtain structurally diverse metabolites or increase the production of the known products [7]. In nature there are no pure cultures and the interactions among the microbial populations are responsible for the biosynthetic pathways of their secondary metabolism. Therefore, the co-culturing of species in microbial fermentation is a tool able to mimic the natural environment where competition-collaboration relations occur among microorganisms.

Nigericin (Figure 1), which has also been reported with other names, such as polyetherin A and antibiotic X-464, is a polycyclic polyether produced by various Streptomyces strains [14,15]. It displays strong antibacterial, antifungal, and antimalarial activities [16], it acts as an inflammasome-inducing agent [17] and is able to inhibit the replication of human cytomegalovirus [18]. Recent studies have highlighted its antitumor properties; in fact, it is able to suppress colorectal cancer metastasis [19], block the proliferation of cancer stem cells of different tumor types, both in vitro and in vivo [20,21], and to inhibit the proliferation of multidrug-resistant lung cancer cells [22].

Very recently we have reported on the metabolites produced by the SF10 strain obtained from a semi-arid Algerian soil and identified as Streptomyces youssoufiensis, whose secondary metabolite profile had been not yet studied. The ionophoric polyethers nigericin, epinigericin, abierixin and the newly isolated grisorixin methyl ester were isolated in pure form from the crude ethyl acetate extract, and their structures were fully characterized by mass spectrometry and extensive NMR analysis. Furthermore, we observed that both nigericin and grisorixin methyl ester affected human glioblastoma stem cell proliferation in a dose-dependent manner, with promising $\mathrm{GI}_{50}$ values compared with the currently used drug, temozolomide [23].

In the present work we communicate the optimization of nigericin production by the SF10 strain, with a special focus on the investigation of the different culture conditions able to affect the production of this metabolite. Nigericin production was quantitatively evaluated by an efficient chromatographic analysis of the bacterial crude extracts, which allowed the selection of the best culture conditions. 


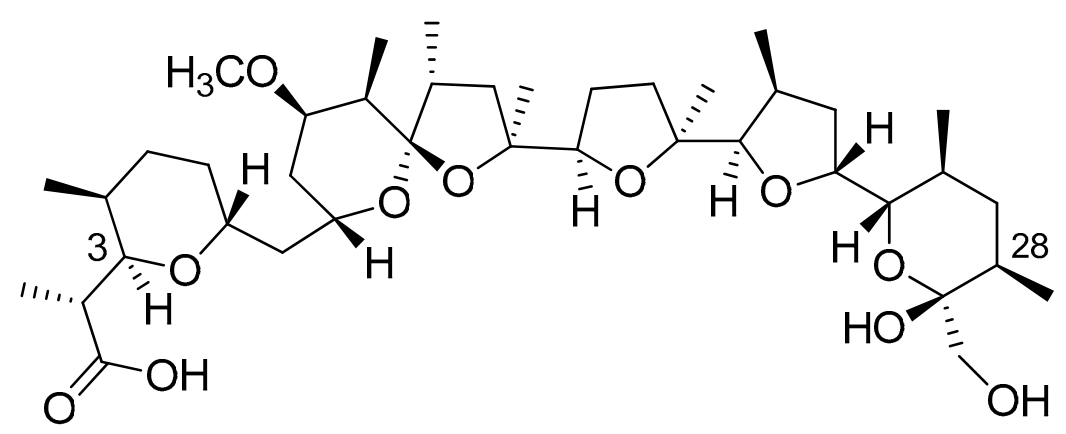

Figure 1. Molecular structure of nigericin.

\section{Materials and Methods}

\subsection{Isolation and Identification of the Bacterial Strain}

A semi-arid soil sample (10 g) collected at Chélia Mountain $\left(35^{\circ} 19^{\prime} 6^{\prime \prime} \mathrm{N}, 6^{\circ} 38^{\prime} 15^{\prime \prime} \mathrm{E}\right)$, in Khenchela (Northeastern Algeria), was diluted in $100 \mathrm{~mL}$ of sterile distilled water. The mixture was allowed to settle, and then serial ten-fold dilutions were prepared. An aliquot $(0.1 \mathrm{~mL})$ was taken from each dilution and spread evenly over the surface of an Olson medium containing polymexin and nystatin (each at a concentration of $50 \mu \mathrm{g} / \mathrm{mL}$ ). Plates were incubated at $30^{\circ} \mathrm{C}$ for 14 days. Colonies of members of the Actinomycetale order were picked and purified by serial subcultures on yeast-malt extract agar (YMEA) medium. The strain was selected from the 11 Actinomycetale strains obtained, based on its ability to inhibit the growth of pathogenic and phytopathogenic bacteria (methicillin-resistant Staphylococcus aureus and Bacillus subtilis) as well as fungi (Fusarium oxysporum). Details on the strain identification were reported by Leulmi et al. [23].

\subsection{Crude Extracts}

Pure culture of the SF10 strain was used to inoculate plates of Bennett's agar medium. After an incubation period of 14 days at $30^{\circ} \mathrm{C}$, the mycelial mass together with the culture medium was cut into small pieces, subjected to sonication and then macerated overnight in ethyl acetate (EtOAc). The resulting mixture was filtered, and the maceration was repeated twice. The combined filtrates were evaporated in vacuo to give a yellow crude extract $(1.0 \mathrm{~g})$. A similar procedure was performed to obtain the extracts from the strain cultured using solid state fermentation under different conditions (carbon source, $\mathrm{pH}, \mathrm{FeSO}_{4}$, co-culture). In the submerged fermentation ( $\mathrm{SmF}$ ) case, the precultured isolate was transferred into $500 \mathrm{~mL}$ Erlenmeyer flasks containing $100 \mathrm{~mL}$ of fermentation medium $(10 \%)$ and incubated on a rotary shaker. The fermentation broth was centrifuged $\left(10 \mathrm{~min}\right.$, at $4{ }^{\circ} \mathrm{C}$ for $15,000 \times g)$ to separate the mycelium from the supernatant. Cell-free supernatant $(100 \mathrm{~mL}) \mathrm{was}$ extracted with EtOAc $(100 \mathrm{~mL})$ to obtain a crude extract.

\subsection{Culture Conditions of the Bacterial Strain Used to Maximize Nigericin Production}

\subsubsection{Selection of the Fermentation Process}

Two different processes of fermentation, SSF and SmF, were used. In SSF process, the strain was grown on two Petri dishes containing the selected basal medium (Bennett's medium) and the extraction of secondary metabolites was carried out as reported above. In the SmF method, the active strain was precultured in $50 \mathrm{~mL}$ flasks containing $10 \mathrm{~mL}$ of broth medium, at $30{ }^{\circ} \mathrm{C}$ for 3 days. The precultured isolate was transferred into $500 \mathrm{~mL}$ Erlenmeyer flasks containing $100 \mathrm{~mL}$ of fermentation medium $(10 \%)$ and incubated on a rotary shaker. The fermentation broth was centrifuged $\left(10 \mathrm{~min}\right.$, at $4{ }^{\circ} \mathrm{C}$ for $15,000 \times g)$ to separate the mycelium from the supernatant. Cell-free supernatant $(100 \mathrm{~mL}) \mathrm{was}$ extracted with EtOAc $(100 \mathrm{~mL})$ to obtain a crude extract which was analyzed by the HPLC-evaporative light scattering detector (ELSD) technique. The experiments were performed in duplicate. 


\subsubsection{Carbon Sources, $\mathrm{pH}$ Values, Presence of $\mathrm{FeSO}_{4}$ and $\mathrm{Co}-\mathrm{Culture}$ Conditions}

All media were inoculated with pure culture of the strain under investigation and incubated at $30{ }^{\circ} \mathrm{C}$ for 14 days. The components of the basal medium were kept constant. The carbon sources tested included monosaccharides (D-glucose, and (D-ribose), disaccharides (sucrose), complex carbon sources (starch), and sugar alcohol (mannitol), used in $10 \mathrm{~g} / \mathrm{L}$ concentrations. The $\mathrm{pH}$ values tested, growing the strain in the basal medium in the presence of the optimum carbon source (D-glucose), were 5,7 and 11. The effect of the presence of $\mathrm{FeSO}_{4}$ was evaluated by growing the strain in Bennett's medium at $\mathrm{pH} 7$ supplemented with aqueous solution of $\mathrm{FeSO}_{4}(0.5$ and $1 \mathrm{~g} / \mathrm{L})$. Finally, the strain was co-cultured separately with Streptomyces sp. (accession number KX575868) and S. coeruleorubidus (accession number KU373055), isolated from a semi-arid rhizospheric-associated soil of Khenchela (Algeria). The EtOAc crude extracts were obtained as described above. All the experiments were performed in duplicate.

\subsection{Calibration Curve Construction, Evaluation of the Detection Limit and Quantitative Analysis of Nigericin Produced under Different Culture Conditions}

Solvents were purchased from Sigma Aldrich Europe or Alfa Aesar and were used without any further purification. An Agilent 1200 high-performance liquid chromatography (HPLC) system was equipped with an autosampler, a binary pump, a diode array detector (Agilent Technologies Waldbronn, Germany) and an evaporative light scattering detector (ELSD). Separation was performed on an Eclipse $\mathrm{C} 183.5 \mu \mathrm{m}$ analytical column, setting the temperature of the column at $40{ }^{\circ} \mathrm{C}$. A gradient elution $(1 \mathrm{~mL} / \mathrm{min}$ flow rate) was performed using A (methanol/water, 9:1 ratio, 0.1\% TFA from 0 to $25 \mathrm{~min}$ ) and B (methanol, 100\%, 0.1\% TFA, from 25 to $50 \mathrm{~min}$ ). A solution of nigericin previously isolated by the same SF10 strain [23] (10 $\mu \mathrm{L}, 1 \mathrm{mg} / \mathrm{mL}$ in methanol) was used to create several diluted solutions $(1,0.5,0.2$ and $0.1 \mathrm{mg} / \mathrm{mL})$, which were injected in the HPLC apparatus. The calibration curve was obtained by plotting ELSD peak area versus the concentration of the chemical. ChemStation software was used to integrate the area under the chromatographic peaks. The linearity of the curve was evaluated by regression analysis, which was calculated using the least square method. The limit detection (LOD) value was experimentally verified by injecting different standard solutions which were more diluted. Subsequently, the EtOAc extracts obtained by cultures of the Streptomyces SF10 strain under different conditions previously described were directly injected into the HPLC system, using an injection volume of $10 \mu \mathrm{L}$. The amount of nigericin present in each extract was calculated by interpolation with the calibration curve.

\subsection{Phenylacetic Acid from Fermentation in Streptomyces sp. co-Culture}

\subsubsection{NMR and Mass Spectrometric Analysis}

NMR spectra were recorded by an Avance 400 Bruker spectrometer by using a $5 \mathrm{~mm}$ BBI probe. ${ }^{1} \mathrm{H}$ NMR spectra were recorded at $400 \mathrm{MHz}$ and ${ }^{13} \mathrm{C}$ at $100 \mathrm{MHz}$ in $\mathrm{CDCl}_{3}\left(\delta_{\mathrm{H}}=7.25 \mathrm{ppm}\right.$ and $\left.\delta_{\mathrm{c}}=77.0 \mathrm{ppm}\right)$. Structural assignments were supported by heteronuclear single quantum correlation (HSQC) and heteronuclear multiple bond correlation (HMBC) experiments. ESI-MS data and tandem fragmentation spectra (MS/MS) were recorded using a Bruker Esquire LC ion trap mass spectrometer, equipped with an electrospray ion (ESI) source in positive or negative ion mode, by injection of a methanolic solution of the sample into the source. MS conditions were: source temp. $300{ }^{\circ} \mathrm{C}$, nebulizing gas $\mathrm{N}_{2}, 4 \mathrm{~L} / \mathrm{min}$, cone voltage $32 \mathrm{~V}$, scan range $m / z$ 100-900. Fragmentation experiments were carried out using Helium to collisionally activate the selected primary ions.

\subsubsection{Isolation and Structural Characterization of the Metabolite}

Crude extract (22 mg) from the liquid co-culture of the SF10 strain with Streptomyces sp. (KX575868) using Bennett's medium in SmF conditions was fractionated by flash chromatography on a reversed 
phase RP-18 column (RP-FC) and eluted with $\mathrm{MeOH} /$ water gradient mode. A pure compound (20 mg) was obtained and analyzed by NMR and EI-MS techniques.

${ }^{1} \mathrm{HNMR}\left(\mathrm{CDCl}_{3}, 400 \mathrm{MHz}\right): 83.64\left(2 \mathrm{H}, \mathrm{s}, \mathrm{CH}_{2}\right) 7.36-7.26(5 \mathrm{H}$, series of $\mathrm{m}, \mathrm{Ph}) .{ }^{13} \mathrm{CNMR}\left(\mathrm{CDCl}_{3}\right.$, $100 \mathrm{MHz}): \delta 177.25,133.44,129.38(\times 2), 128.64(\times 2), 127.31,41.10$. Protons in $\mathrm{CH}_{2}$ unit at $3.64 \mathrm{ppm}$ were correlated to $\mathrm{COOH}$ at $177.25 \mathrm{ppm}$, to the aromatic signals at $133.44 \mathrm{ppm}$ and $129.38 \mathrm{ppm}$ by HMBC experiment. ESI(-)-MS: $m / z 135[\mathrm{M}-\mathrm{H}]^{-}$.

\section{Results and Discussion}

\subsection{Metabolite Production under Different Culture Conditions}

In order to investigate and optimize the culture conditions affecting nigericin production by the SF10 strain, different parameters were taken into account, including the fermentation conditions, the carbon source used as the nutrient, the $\mathrm{pH}$ of the medium, the presence of $\mathrm{FeSO}_{4}$ and the co-culturing with another microorganism. The fermentation processes considered were the SSF and submerged fermentation, as described in Materials and Methods. SSF resulted in the best process, so it was adopted as the fermentation method in the following investigation of culture conditions. All media were inoculated with a pure culture of SF10, at constant values of the components of the basal medium. The tested carbon sources included monosaccharides, disaccharides, starch, mannitol, and the use of D-glucose resulted in the optimal condition. Using D-glucose, the growth of the strain was then tested at $\mathrm{pH} 5,7$ and 11 in the basal medium.

The effect of $\mathrm{FeSO}_{4}$ presence was evaluated by growing the strain in Bennett's medium supplemented with an aqueous solution of $\mathrm{FeSO}_{4}$ at two different concentration values.

The SF10 strain was also co-cultured with Streptomyces sp. or Streptomyces coeruleorubidus using Bennett's agar medium at pH 7 and D-glucose as the carbon source. Both the co-cultures in SSF conditions caused a decrease in the nigericin production, as established by the method reported below. In addition, the growth of the strain was very slow and without sporulation, different from its growth in monoculture. This represents additional evidence supporting the idea that the mycelium morphology correlates with the production of secondary metabolites [24].

The submerged fermentation conditions provided more selective behavior in the presence of the two strains used. Streptomyces sp. co-culture strongly affected the metabolite production, as nigericin was not produced at all. NMR analysis of the crude extract showed a series of very minor unidentified compounds and a major metabolite, identified as phenylacetic acid, by comparing NMR and MS spectra with the reported data [25,26]. Comparison between the molecular complexity of nigericin and the structural simplicity of phenylacetic acid gives an idea of the ability of Streptomyces spp. to produce metabolites with a wide chemical variety and a broad spectrum of bioactivity. Phenylacetic acid, previously isolated from $S$. humidus cultures, has shown antifungal effects against some plant-pathogenic fungi [25].

By co-culturing the SF10 strain with S. coeruleorubidus in SmF conditions, neither nigericin nor phenyl acetic acid was detected by HPLC-ELSD analysis.

\subsection{Quantitative Method for Nigericin Evaluation}

Considerable efforts have been undertaken in recent years to develop accurate and sensitive methods for the characterization and quantification of ionophoric compounds [27] and a number of analyses have been specifically performed on nigericin using the LC-MS technique [14]. In order to quantitatively detect the nigericin amount present in crude extracts obtained from the strain grown under different culture conditions, we developed a method based on the use of a chromatographic system equipped with an ELSD. The HPLC-ELSD technique allows us to analyze compounds unable to absorb UV radiation efficiently, as in the case of nigericin which lacks significant chromophores in its molecular structure. In addition, providing a stable baseline even in conditions of gradient elution, the ELSD represents an excellent detector for quantitative analysis. Analyses based on a HPLC system 
equipped with an ELSD have shown a modest error in the contemporary quantitative evaluation of structurally diverse natural products, and the number of applications employing this technique is constantly growing.

Using a sample of pure nigericin previously isolated by the same SF10 strain [23], a calibration curve was constructed by plotting the ELSD response area versus nigericin concentration. The obtained calibration curve presented a very good linear fit (Figure 2). A detection limit corresponding to $1 \mu \mathrm{g} / \mathrm{mL}(1.38 \mu \mathrm{M})$ was also determined.

(a)

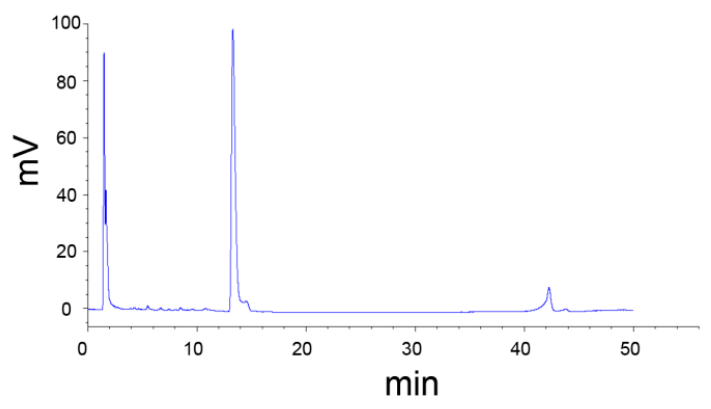

(b)

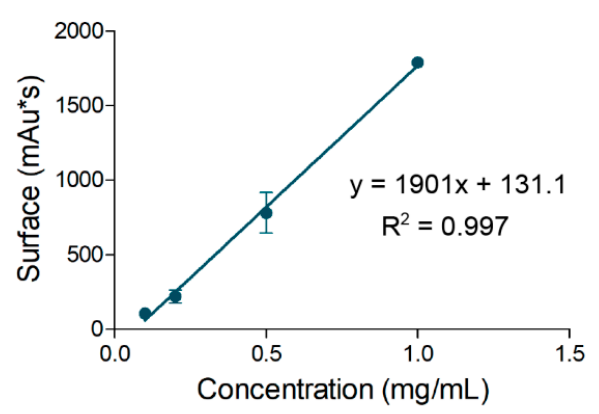

Figure 2. Quantitative analysis of nigericin determined by HPLC-evaporative light scattering detector (ELSD) analysis (RP-18, $\mathrm{MeOH} / \mathrm{H}_{2} \mathrm{O}+0.1 \%$ TFA gradient elution): (a) a representative chromatogram showing nigericin peak at $12.1 \mathrm{~min}$, obtained by injecting the ethyl acetate extract from the SF10 strain cultured in solid state fermentation (SSF), D-glucose, $\mathrm{pH}$ 7, by incubation of 14 days at $30{ }^{\circ} \mathrm{C}$; (b) calibration curve built using pure nigericin.

\subsection{Comparative Analysis of Nigericin Production}

The EtOAc crude extracts, obtained from the SF10 strain cultured in solid state fermentation for 14 days at $30{ }^{\circ} \mathrm{C}$ under the conditions previously described, were subjected to HPLC-ELSD analysis. Interpolation of each peak detected at $12.1 \mathrm{~min}$, attributed to nigericin by comparison with a standard sample, provided the concentration value of the metabolite present in each extract.

Our results confirm the environmental influence on the production of secondary metabolites by Streptomyces strains [28]. SSF was the most efficient fermentation condition for nigericin production. In fact, in this condition, the SF10 strain was able to produce a considerable amount of the metabolite, similar to reported cases [10]. The influence of a carbon source on nigericin production was evaluated by growing the strain in SSF at pH 7. D-glucose emerged as the most favorable among all the carbon sources tested, yielding a nigericin concentration of $0.49 \mathrm{mg} / \mathrm{mL}$, to which a $100 \%$ relative abundance was assigned in Figure 3. This behavior recalls that of S. hygroscopicus for the production of polyether antibiotics [29] and of S. griseus for the synthesis of dinactin [30]. Replacing glucose with other carbon sources negatively affected the relative amounts of nigericin, which decreased to $15.2 \pm 0.3 \%$ using ribose, to $33.2 \pm 3 \%$ using the sugar alcohol mannitol, and was totally abrogated by the use of sucrose or starch (Figure 3a).

Several metal ions, including zinc, iron and manganese, affect bacteria growth and can stimulate or suppress metabolite production [31]. Iron ions play a significant role in the biosynthesis of complex polyethers, depending on their concentration in the basal medium [29]. In line with these findings we observed that the presence of iron (II) sulfate affected the growth of the SF10 strain. We found that the increasing addition of iron (II) sulfate significantly inhibited the production of nigericin, reducing its amount to $31 \pm 4 \%$ using $0.5 \mathrm{~g} / \mathrm{L}$ and to $9.5 \pm 0.7 \%$ using $1 \mathrm{~g} / \mathrm{L}$ (Figure $3 \mathrm{~b}$ ).

A variation in nigericin production was also observed as a function of acidity/basicity of the medium. The highest relative amount was obtained by fermentation of the strain in the presence of glucose at neutral $\mathrm{pH}$ (Figure $3 \mathrm{a})$, whereas a decreased production $(23 \pm 4 \%)$ was observed at $\mathrm{pH} 11$, and no production was detected at $\mathrm{pH} 5$ (Figure 3c). It is notable that the related polyether, abierixin, 
which shows an open $\mathrm{O}-\mathrm{C} 3$ structural change upon acidic or basic treatments [32], was not detected as an appreciable conversion of nigericin at 5 or $11 \mathrm{pH}$ values.

SF10 strain co-cultured in solid state conditions with D-glucose at $\mathrm{pH} 7$ with Streptomyces sp. and S. coeruleorubidus provided a production of nigericin evaluated at $5.4 \pm 1.5 \%$ and $5.0 \pm 0.1 \%$, respectively (Figure 3d). Otherwise, similar culture conditions that replaced solid state with submerged fermentation gave no nigericin.

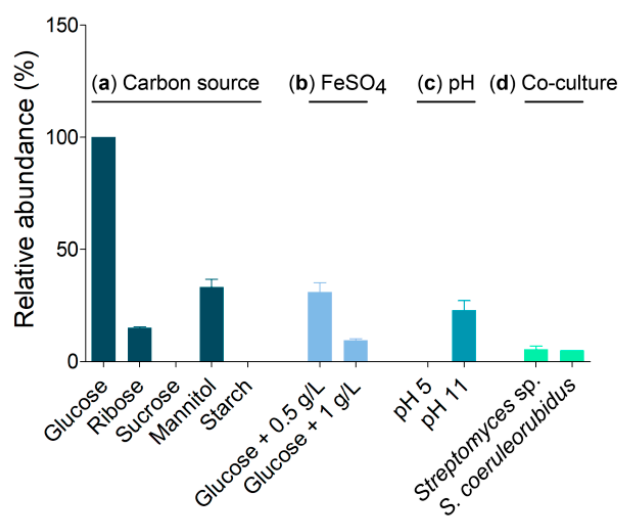

Figure 3. Relative nigericin production by the Streptomyces youssoufiensis SF10 strain cultured in Bennett's agar medium using SSF for 14 days at $30{ }^{\circ} \mathrm{C}$ : (a) different carbon sources at $\mathrm{pH} 7$; (b) D-glucose supplemented by iron (II) sulfate at $\mathrm{pH} 7$ at the indicated concentration values; (c) D-glucose at different $\mathrm{pH}$ values; (d) D-glucose at $\mathrm{pH}$ 7, co-culture with Streptomyces sp. and S. coeruleorubidus.

In summary, the highest production of nigericin was obtained by growing S. youssoufiensis SF10 in single culture using SSF and D-glucose at $\mathrm{pH} 7$ for 14 days at $30^{\circ} \mathrm{C}$. These conditions pushed the metabolite production to the maximum value of concentration of $0.49 \mathrm{mg} / \mathrm{mL}$. This amount of nigericin is remarkable if compared with its first isolation in $50-100 \mu \mathrm{g} / \mathrm{mL}$ from an unidentified Streptomyces [33], as well as with one produced by S. albus NRRL B-1865 estimated approximately at $0.1 \mathrm{mg} / \mathrm{mL}$ [34] and that obtained from the mutant A-19 of S. hygroscopicus $(0.318 \mathrm{mg} / \mathrm{mL})$ [35].

\section{Conclusions}

The effect of different culture conditions (solid state or submerged fermentation, carbon source, $\mathrm{pH}$ values, presence of iron (II) sulfate, and co-culture with other microorganisms) on the production of nigericin by the Algerian soil-derived SF10 strain Streptomyces youssoufiensis was investigated. The evaluation was carried out by a quantitative method based on the HPLC-ELSD analysis of the crude extracts and on the use of a calibration curve. The work allowed us to select the best parameters and culture conditions to obtain an optimized production of nigericin, which presents interesting antibiotic activity and recently reported promising antitumor effects. The quantitative method employed here in the detection of nigericin can find wider successful applications in the analysis of crude extracts containing a wide series of polycyclic polyether metabolites or other metabolites lacking significant chromophore units in their molecular structure.

Author Contributions: Conceptualization, I.M. and A.B.; Methodology, N.L. and K.K.; Software, A.D.; Validation, N.L., and D.S.; Formal Analysis, N.L.; Data Curation, N.L. and D.S.; Writing-Original Draft Preparation, I.M.; Writing-Review \& Editing, D.S. and A.D.; Supervision, I.M..; Funding Acquisition, A.B.

Funding: This work was supported by the Algerian Ministry of Higher Education which provided grants for L.N. stage at the University of Trento.

Acknowledgments: The authors are grateful to Adriano Sterni and Mario Rossi, University of Trento, for their technical support in mass spectrometry and HPLC-ELSD chromatography, respectively.

Conflicts of Interest: The authors declare no conflict of interest. 


\section{References}

1. Mohammadipanah, F.; Wink, J. Actinobacteria from arid and desert habitats: Diversity and biological activity. Front. Microbiol. 2016, 6, 1541. [CrossRef] [PubMed]

2. Bamdad, M.; David, L.; Groliére, C.A. Epinigericin toxicity towards Tetrahymena pyriformis GL; changes in cell volume and intracellular pH. Appl. Microbiol. Biotechnol. 1995, 44, 206-209. [CrossRef] [PubMed]

3. Smith, L.; Hong, H.; Spencer, J.B.; Leadaly, P.F. Analysis of specific mutants in the lasalocid gene cluster: Evidence for enzymatic catalysis of a disfavoured polyether ring closure. ChemBioChem 2008, 9, 2967-2975. [CrossRef] [PubMed]

4. Elibol, M.; Mavituna, F. Effect of sucrose on actinorhodin production by Streptomyces coelicolor A3(2). Proc. Biochem. 1998, 33, 307-311. [CrossRef]

5. Djinni, I.; Defant, A.; Kecha, M.; Mancini, I. Metabolite profile of marine-derived endophytic Streptomyces sundarbansensis WR1L1S8 by liquid chromatography-mass spectrometry and evaluation of culture conditions on antibacterial activity and mycelial growth. J. Appl. Microbiol. 2013, 116, 39-50. [CrossRef]

6. Jounsbu, E.; McIntyre, M.; Nielsen, J. The influence of carbon sources and morphology on nystatin production by Streptomyces noursei. J. Biotechnol. 2002, 95, 133-144. [CrossRef]

7. Dashti, Y.; Grkovic, T.; Abdelmohsen, U.R.; Hentschel, U.J.; Quinn, R. Production of induced secondary metabolites by a co-culture of sponge-associated Actinomycetes, Actinokineospora sp. EG49 and Nocardiopsis sp. RV163. Mar. Drugs 2014, 12, 3046-3059. [CrossRef]

8. Elibol, M. Optimization of medium composition for actinorhodin production by Streptomyces coelicolor A3(2) with response surface methodology. Process. Biochem. 2004, 39, 1057-1062. [CrossRef]

9. Singh, V.; Haque, S.; Niwas, R.; Srivastava, A.; Pasupuleti, M.; Tripathi, C.K. Strategies for fermentation medium optimization: An in-depth review. Front. Microbiol. 2017, 7, 2087. [CrossRef]

10. Subramaniyam, R.; Vimala, R. Solid state and submerged fermentation for the production of bioactive substances: A comparative study. Int. J. Sci. Nat. 2012, 3, 480-486.

11. Hölker, U.; Lenz, J. Solid-state fermentation-Are there any biotechnological advantages? Curr. Opin. Microbiol. 2005, 8, 301-306. [CrossRef] [PubMed]

12. Rueda, B.; Miguelez, E.M.; Hardisson, C.; Manzanal, M.B. Mycelial differentiation and spore formation by Streptomyces brasiliensis in submerged culture. Can. J. Microbiol. 2001, 47, 1042-1047. [CrossRef] [PubMed]

13. Shu, C.H.; Lung, M.Y. Effect of the $\mathrm{pH}$ on the production and molecular weight distribution of exopolysaccharide by antrodia camphorate in batch cultures. Process Biochem. 2004, 39, 931-937. [CrossRef]

14. Harvey, M.B.; Mironenko, T.; Sun, Y.; Hong, H.; Deng, Z.; Leadlay, F.P.; Weissman, J.K.; Haydock, S.F. Insights into polyether biosynthesis from analysis of the nigericin biosynthetic gene cluster in Streptomyces sp. DSM 4137. Chem. Biol. 2007, 14, 703-714. [CrossRef] [PubMed]

15. Taechowisan, T.; Chanaphat, S.; Ruensamran, W.; Phutdhawong, W.S. Antibacterial activity of 1-methyl ester-nigericin from Streptomycxes hygroscopicus BR10: An endophyte in Alpinia galanga. J. Appl. Pharm. Sci. 2013, 3, 104-109. [CrossRef]

16. Gumila, C.; Ancelin, M.L.; Delort, A.M.; Jeminet, G.; Vialj, H. Characterization of the potent in vitro and in vivo antimalarial activities of ionophore compounds. Antimicrob. Agents Chemother. 1997, 41, 523-529. [CrossRef] [PubMed]

17. Bilen, S.; Biswas, G.; Otsuyama, S.; Kono, T.; Sakai, M.; Hikima, J.I. Inflammatory responses in the Japanese pufferfish (Takifugu rubripes) head kidney cells stimulated with an inflammasome-inducing agent, nigericin. Dev. Comp. Immunol. 2014, 46, 222-230. [CrossRef]

18. Kapoor, A.; He, R.; Venkatadri, R.; Forman, M.; Arav-Boger, R. Wnt modulating agents inhibit human cytomegalovirus replication. Antimicrob. Agents Chemother. 2013, 57, 2761-2767. [CrossRef]

19. Zhou, H.M.; Dong, T.T.; Feng, L.L.; Feng, B.; Zhao, H.C.; Fan, X.K.; Zheng, M.H. Suppression of colorectal cancer metatstasis by nigericin through inihition of epithelial-mesenchymal transition. World J. Gastroenterol. 2012, 18, 2640-2648. [CrossRef]

20. Deng, C.C.; Liang, Y.; Wu, M.S.; Feng, F.T.; Hu, W.R.; Chen, L.Z.; Feng, Q.S.; Bei, J.X.; Zeng, Y.X. Nigericin selectively targets cancer stem cells in nasopharyngeal carcinoma. Int. J. Biochem. Cell Biol. 2013, 45, 1997-2006. [CrossRef] 
21. Hegazy, A.M.; Yamada, D.; Kobayashi, M.; Kohno, S.; Ueno, M.; Ali, M.A.E.; Ohta, K.; Tadokoro, Y.; Ino, Y.; Todo, T.; et al. Therapeutic strategy for targeting aggressive malignant gliomas by disrupting their energy balance. J. Biol. Chem. 2016, 291, 21496-21509. [CrossRef] [PubMed]

22. Yakisich, J.S.; Azad, N.; Kaushik, V.; O’Doherty, G.A.; Iyer, A.K.V. Nigericin decreases viability of multidrug-resistant cancer cells and lung tumorspheres and potentiates the effects of cardiac glycosides. Tumor Biol. 2017, 39. [CrossRef] [PubMed]

23. Leulmi, N.; Sighel, D.; Defant, A.; Khenaka, K.; Boulahrouf, A.; Mancini, I. Nigericin and grisorixin methyl ester from the Algerian soil-living Streptomyces youssoufiensis SF10 strain: A computational study on their epimeric structures and evaluation of glioblastoma stem cells growth inhibition. Nat. Prod. Res. 2018, 1-8. [CrossRef] [PubMed]

24. Manteca, A.; Alvarez, R.; Salazar, N.; Yague, P.; Sanchez, J. Mycelium differentiation and antibiotic production in submerged culture of Streptomyces celicolor. Appl. Environ. Microbiol. 2008, 74, 3877-3886. [CrossRef] [PubMed]

25. Hwang, B.K.; Lim, S.W.; Kim, B.S.; Lee, J.Y. Isolation and in vivo and in vitro antifungal activity of phenylacetic acid and sodium phenylacetate from Streptomyces humidus. Appl. Environ. Microbiol. 2001, 67, 3739-3745. [CrossRef] [PubMed]

26. Kim, Y.; Cho, J.Y.; Kuk, J.H.; Moon, J.H.; Cho, J.; Kim, Y.C.; Park, K.H. Identification and antimicrobial activity of phenylacetic produced by Bacillus licheniformis isolated from fermented soybean, Chungkook-Jang. Curr. Microbiol. 2004, 48, 312-317. [CrossRef] [PubMed]

27. Crevelin, E.J.; Crotti, A.E.M.; Zucchi, T.D.; Melo, I.S.; Moraes, L.A.B. Dereplication of Streptomyces sp. AMC 23 polyether ionophore antibiotics by accurate mass electrospray tandem mass spectrometry. J. Mass Spectrom. 2014, 49, 1117-1126. [CrossRef]

28. Shahab, N.; Kamaruddin, K.; Platt, J.; Butler, P.R.; Olivier, S.G.; Hobbs, G. Cell physiology and antibiotic production of Streptomyces coelicolor grown on solid medium. Biotechnol. Lett. 1994, 16, 1015-1020. [CrossRef]

29. Darakchieva, M.; Ratchev, R.; Sachanekova, M.; Tzvetkova, R.; Gameyska, Y.O.; Popov, K.; Roussev, P.; Schlegel, R.; Kleinwachter, W.; Thrum, H. Polyether antibiotic complex produced by Streptomyces hygroscopicus IM-110-81. Biotechnol. Bioind. 1987, 2, 15-17. [CrossRef]

30. Zhou, J.; He, H.; Wang, X.; Lu, J.; Zhou, X.; Cai, M.; Zhang, Y. Optimization of nutrients for dinactin production by a marine Streptomyces sp. from the high latitude Arctic. Biotechnol. Bioprocess Eng. 2015, 20, 725-732. [CrossRef]

31. Gesheva, V.; Ivanova, V.; Gesheva, R. Effects of nutrients on the production of AK-111-81 macrolide antibiotic by Streptomyces hygroscopicus. Microbiol. Res. 2005, 160, 243-248. [CrossRef] [PubMed]

32. Dauphin, G.; David, L.; Kergomard, A.; Sainz, C. Nigericic acids, two new chemical derivatives of nigericin. Agric. Biol. Chem. 1989, 53, 2497-2498. [CrossRef]

33. Harned, R.L.; Hidy, P.H.; Corum, C.J.; Jones, K.L. Nigericin a new crystalline antibiotic from an unidentified Streptomyces. Antibiot. Chemother. 1951, 1, 594-596.

34. David, L.; Leal Ayala, H.; Tabet, J.C. Abierixin, a new polyether antibiotic. Production, structural determination and biological activities. J. Antibiot. 1985, 31, 1655-1663. [CrossRef]

35. Xiao, L.; Huang, W.Y. Improvement of fermentation conditions for nigericin produced by Streptomyces hygroscopicus NND-52. Zhongguo Yiyao Gongye Zazhi (Chin. J. Pharm.) 2002, 33, 375-377.

(C) 2019 by the authors. Licensee MDPI, Basel, Switzerland. This article is an open access article distributed under the terms and conditions of the Creative Commons Attribution (CC BY) license (http://creativecommons.org/licenses/by/4.0/). 